\title{
ROLE OF MOLYBDENUM IN ACICULAR FERRITE FORMATION UNDER CONTINUOUS COOLING IN A MEDIUM CARBON MICROALLOYED FORGING STEEL
}

\author{
C. García de Andrés ${ }^{*}$, C. Capdevila*, I. Madariaga** and I. Gutiérrez ${ }^{* *}$ \\ * Department of Physical Metallurgy, Centro Nacional de Investigaciones Metalúrgicas (CENIM), Consejo \\ Superior de Investigaciones Científicas (CSIC), Avda. Gregorio del Amo, 8. 28040 Madrid, Spain. \\ ** Centro de Estudios e Investigaciones Técnicas de Guipúzcoa (CEIT), Pº Manuel Lardizabal, 15, 20009 San \\ Sebastian, Basque Country, Spain
}

Keywords: steels, phase transformations, acicular ferrite

\section{Introduction}

Recent studies have demonstrated that acicular ferrite microstructures can be developed in medium carbon microalloyed forging steels with both isothermal and continuous cooling treatments [1-5]. This subject represents a major and very exciting advance in the technology of steels. However, a deep understanding of the influences that the alloying elements have on the final microstructure should be reached to produce this kind of steels directly by industrial thermomechanical processes.

It is thoroughly accepted that elements such as manganese, sulfur and cooper influence the nucleation of acicular ferrite inside the austenite grains [2,6-7]. The influence of other alloying elements on the evolution of acicular ferrite transformation under isothermal and non-isothermal conditions is not yet well known. Many attempts have been made to describe the effect of molybdenum in alloys [8-15]. Paxton and Bain [9] reported that molybdenum in small proportion exerts a very vigorous effect on hardenability when it is dissolved in austenite. Kinsman and Aaronson [8] justified the experimentally detected reduction in ferrite growth rate in molybdenum containing steels because molybdenum affects the thermodynamic stability of austenite relative to ferrite. A better knowledge of the effects of molybdenum on the evolution of the non-isothermal austenite decomposition could enhance the production of as-forged acicular ferrite microstructures.

The purpose of the present work is to analyze experimentally the influence of molybdenum on the formation of a fully acicular ferrite microstructure in medium carbon microalloyed forging steels under continuous cooling conditions. In this sense, continuous cooling transformation processes of two medium carbon forging steels with different molybdenum content have been investigated. Some isothermal experiments have also been carried out in order to analyze the effect of the Mo on the evolution of acicular ferrite formation.

\section{Materials and Experimental Procedure}

The chemical composition of the two steels studied in this work are given in Table 1.

Table 1Chemical composition (wt \%) of the steels

\begin{tabular}{|l|l|l|l|l|l|l|l|l|l|l|l|l|}
\hline Steel & C & Mn & Si & P & S & Cr & Mo & V & Cu & Al & Ti & N \\
\hline A & 0.37 & 1.45 & 0.56 & 0.010 & 0.043 & 0.04 & 0.025 & 0.11 & 0.14 & 0.024 & 0.015 & 0.0162 \\
\hline B & 0.38 & 1.44 & 0.62 & 0.010 & 0.041 & 0.07 & 0.16 & 0.10 & 0.07 & 0.026 & 0.016 & 0.0122 \\
\hline
\end{tabular}


An Adamel Lhomargy DT1000 high-resolution dilatometer has been used to analyze non-isothermal transformations and to obtain the continuous cooling transformation diagrams (CCT) of these steels. In order to avoid considering the effect of the variation of the prior austenite grain size (PAGS) on non-isothermal transformations, austenitization conditions were selected to achieve approximately the same PAGS in both steels (66 $\mu \mathrm{m}$ ). Thus, cylindrical samples of $2 \mathrm{~mm}$ in diameter and $12 \mathrm{~mm}$ in length of steel A and B were austenitized for $60 \mathrm{~s}$ at $1200{ }^{\circ} \mathrm{C}$ and for $180 \mathrm{~s}$ at $1125^{\circ} \mathrm{C}$, respectively. Subsequently, transformations taking place during continuous cooling at rates ranging from $100 \mathrm{C} \mathrm{s}^{-1}$ to $0.05^{\circ} \mathrm{C} \mathrm{s}^{-1}$ have been dilatometrically analyzed. Cooling is performed by helium flow directly blown onto the sample surface. The dimensional variations of the specimen are measured by a linear variable differential transformer (LVDT). For the isothermal treatments, cubic samples of $10 \mathrm{~mm}$ were austenitized at $1250^{\circ} \mathrm{C}$ for 45 minutes followed by direct quenching in a salt bath in the range $500-400{ }^{\circ} \mathrm{C}$ and hold there to complete the transformation, followed by water quenching to room temperature. The temperature was recorded by a thermocouple into the sample. The cooling rates from the austenitizing to the isothermal treatment temperatures ranged in the interval $800-500{ }^{\circ} \mathrm{C}$ from 27 to $55^{\circ} \mathrm{C} \mathrm{s}^{-1}$, depending on the final temperature. The samples were cut, polished and etched in nital to be observed by optical microscopy.

\section{$\underline{\text { Results and Discussion }}$}

It is generally accepted that austenite decomposition is delayed in molybdenum containing steels leading to an increase in hardenability [9]. In the present work, the influence of molybdenum on the evolution of the austeniteto-acicular ferrite transformation as well as on the morphology of this phase has been investigated.

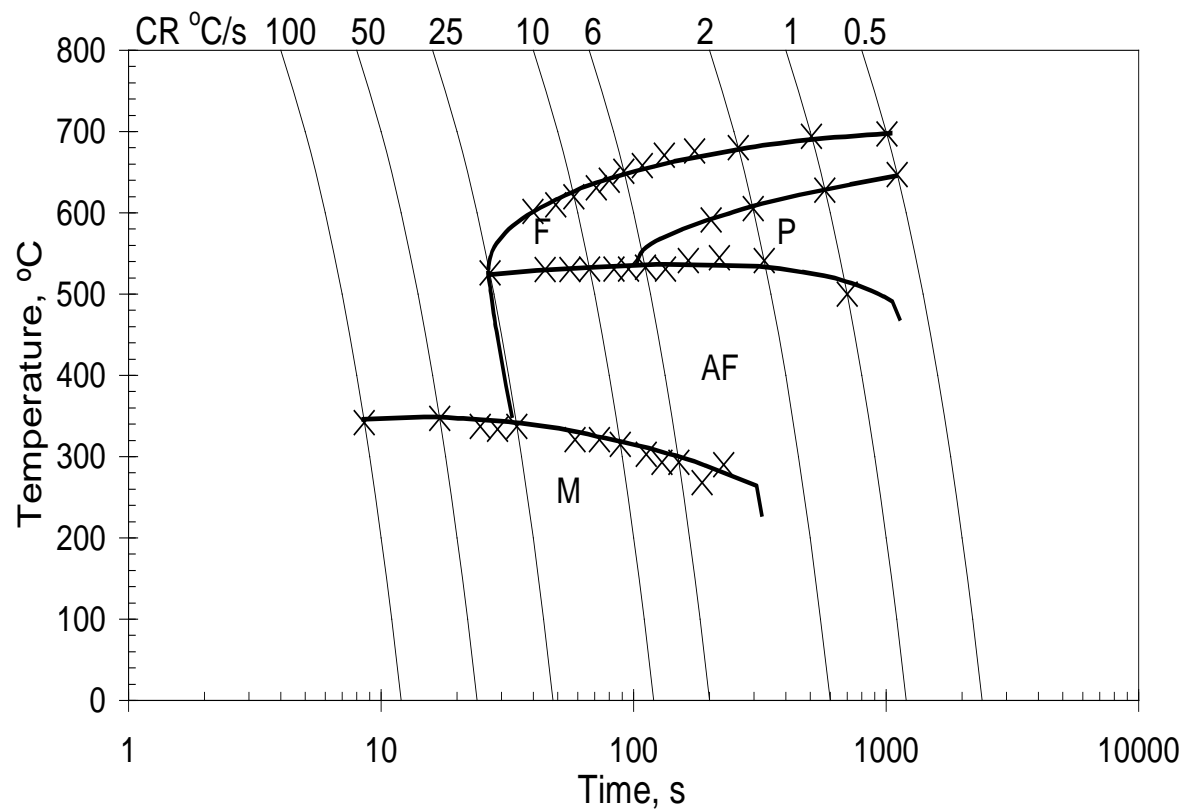

Figure 1. CCT diagram for the steel $\mathrm{A}$, after an austenitization at $1200{ }^{\circ} \mathrm{C} .(\mathrm{F}=$ Allotriomorphic Ferrite, $\mathrm{P}=$ Pearlite, $\mathrm{AF}=$ Acicular Ferrite $\mathrm{M}=$ Martensite and $\mathrm{Ms}=$ Martensite start temperature).

The CCT diagrams of the two steels studied in this work are presented in Figures 1 and 2. Figure 1 shows that the non-isothermal austenite-to-acicular ferrite transformation in steel A occurs at cooling rates ranging from $25 \mathrm{Cs}^{-1}$ to $1 \mathrm{Cs}^{-1}$. The allotriomorphic ferrite formation is avoided cooling down at a rate higher than about $30 \mathrm{Cs}^{-1}$. Pearlite formation is suppressed if the cooling is carried out at a rate of $7 \mathrm{Cs}^{-1}$ or higher. The micrograph in Figure 3 (a) shows that, although pearlite formation is totally inhibited at a cooling rate of $10^{\circ} \mathrm{C} \mathrm{s}^{-1}$, a fine layer of allotriomorphic ferrite which represents approximately the $7 \%$ of the microstructure covers the most part of the prior austenite grain boundaries. The intragranular formation of ferrite leads to a mainly acicular ferrite microstructure for steel A cooled at the above mentioned cooling rate. Nevertheless, the decomposition of austenite does not complete before the martensite start temperature is reached, which causes the apparition of a small amount of martensite at the later stages of the cooling. By contrast, at a cooling rate of $6 \mathrm{C} \mathrm{s}^{-1}$ (Fig. 3(b)), a reduction in 
the final amount of martensite is observed, the volume fraction of allotriomorphic ferrite increases to $10 \%$, and a $2 \%$ of pearlite is also present in the final microstructure. At a cooling rate of $3{ }^{\circ} \mathrm{C} \mathrm{s}^{-1}$ (Fig. 3(c)), significant amounts of allotriomorphic ferrite and pearlite are present in the final microstructure. Cooling rates lower than $2{ }^{\circ} \mathrm{C} \mathrm{s}^{-1}$ would promote the formation of a mixture of allotriomorphic ferrite and pearlite as the main microstructural components.

The formation of an allotriomorphic ferrite layer on the previous austenite grain boundaries is well known [16] to inhibit the formation of bainite and contributes indirectly to the nucleation of AF. However, the steel A presents a high tendency to form an AF microstructure instead of bainite, even in the absence of this ferrite layer. By cooling at a rate between 10 and $2{ }^{\circ} \mathrm{C} \mathrm{s}-1$, the final microstructure is mainly AF. Fully acicular ferrite microstructures have also been obtained in this steel by isothermal treatments [3].

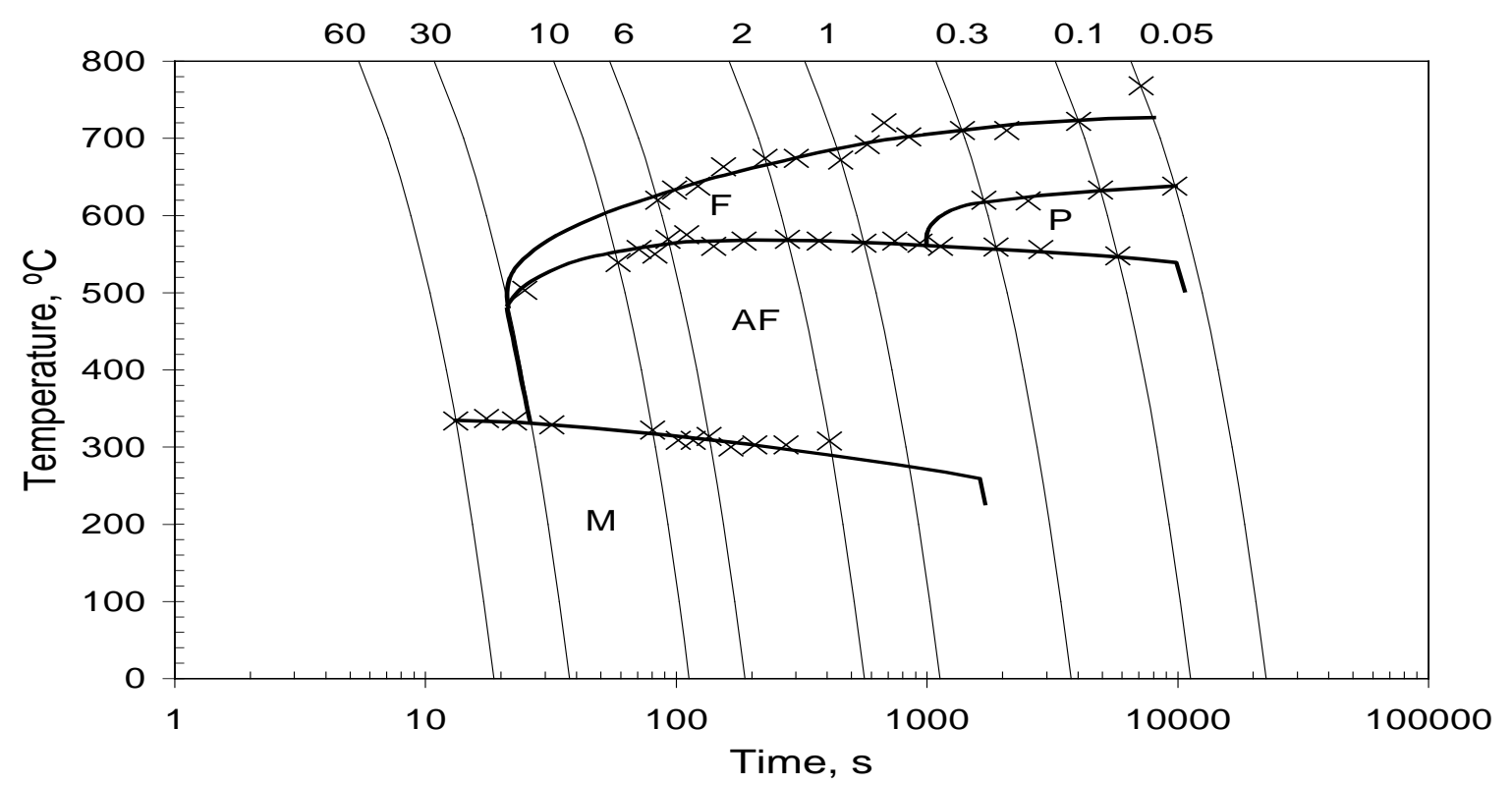

Figure 2. CCT diagram for the steel $\mathrm{B}$, after an austenitization at $1125^{\circ} \mathrm{C}$. $(\mathrm{F}=$ Allotriomorphic Ferrite, $\mathrm{P}=$ Pearlite, $\mathrm{AF}=$ Acicular Ferrite $\mathrm{M}=$ Martensite and $\mathrm{Ms}=$ Martensite start temperature)

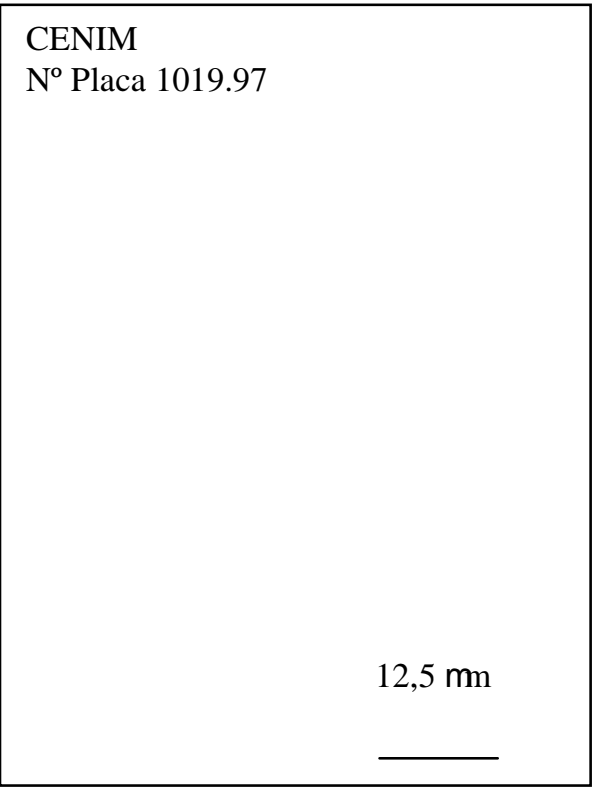

(a)

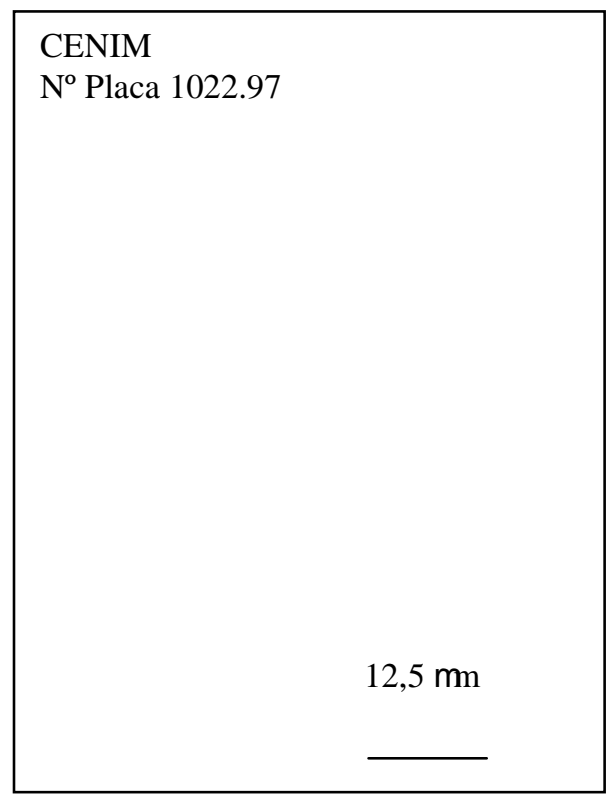

(b)

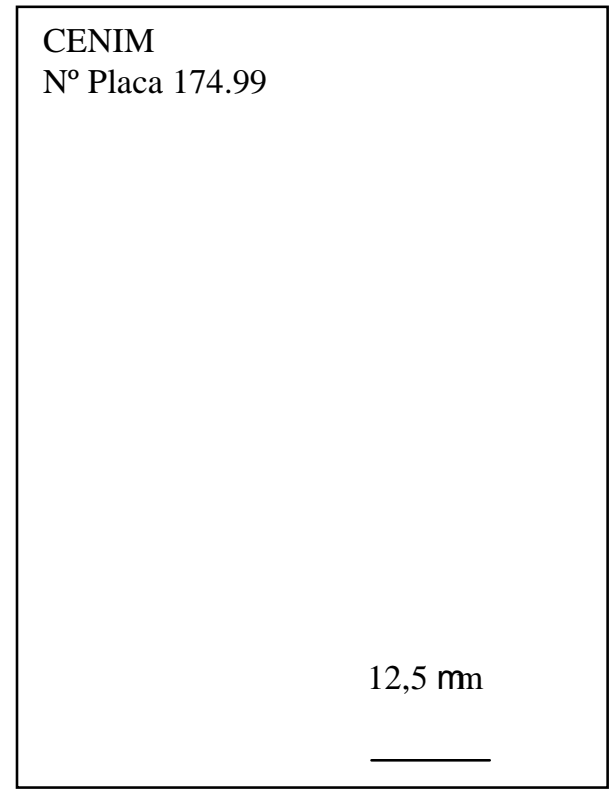

(c)

Figure 3. Microstructures obtained in steel A after the continuous cooling at (a) $10^{\circ} \mathrm{Cs}^{-1}$ (b) $6{ }^{\circ} \mathrm{Cs}^{-1}$ and (c) $3{ }^{\circ} \mathrm{Cs}^{-1}$. 
The addition of Mo to the steel modifies the CCT curves. In comparison with the diagram for steel A in Fig. 1, the pearlite region in the CCT diagram of steel B (Fig. 2) is displaced to longer times. The region corresponding to the acicular ferrite transformation is expanded to lower cooling rates and slightly higher temperatures. It is observed that, like in steel A, the diminution of the allotriomorphic ferrite is not accompanied by the transition from acicular ferrite to bainite formation. As a result, the range of cooling rates leading to the formation of acicular ferrite as the predominant microstructural constituent in the Mo containing steel ranges now from $6{ }^{\circ} \mathrm{Cs}^{-1}$ to $0.3{ }^{\circ} \mathrm{Cs}^{-1}$. The produced microstructures for different cooling rates are shown in Fig. 4. The differences between steels A and B can be understood comparing the micrographs in Figs 3 and 4 . It can be seen that a $10 \%$ of allotriomorphic ferrite is found in steel A upon cooling at $6{ }^{\circ} \mathrm{Cs}^{-1}$ but it is not distinguishable in steel B even at a much lower cooling rate of $0.75^{\circ} \mathrm{C} \mathrm{s}^{-1}$. On the other hand, cooling rates higher than $6^{\circ} \mathrm{Cs}^{-1}$ applied to steel B produce significant amounts of martensite. According to the CCT diagrams in Figs 1 and 2, Mo does not seem to have a large effect on the Ms martensite start temperature on quenching. However, when acicular ferrite forms, the presence of Mo in the steel enhances the apparition of martensite in the final microstructure, even for cooling rates as low as $0.6^{\circ} \mathrm{C} \mathrm{s}^{-1}$. This is probably due to the influence this element has on the transformation kinetics and on the hardenability. In the absence of this element in the steel, martensite formation requires cooling rates higher than $3{ }^{\circ} \mathrm{C} \mathrm{s}^{-1}$.

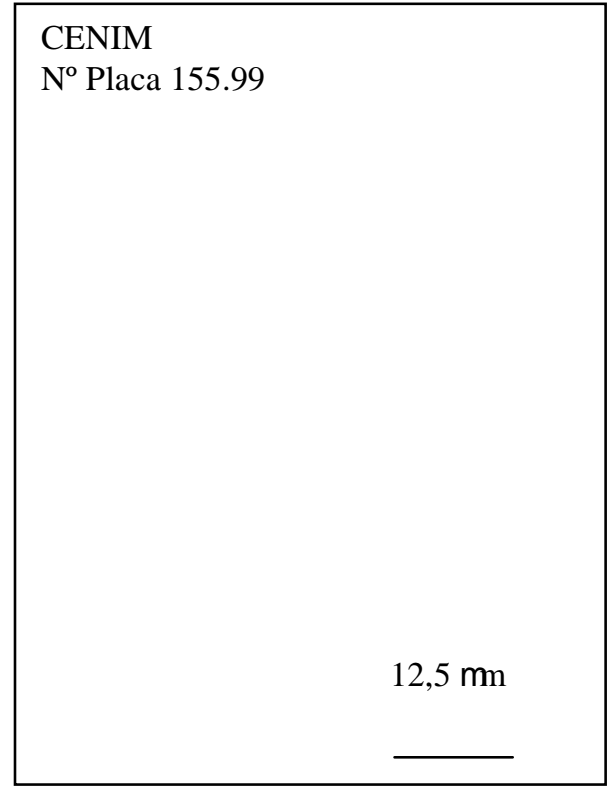

(a)

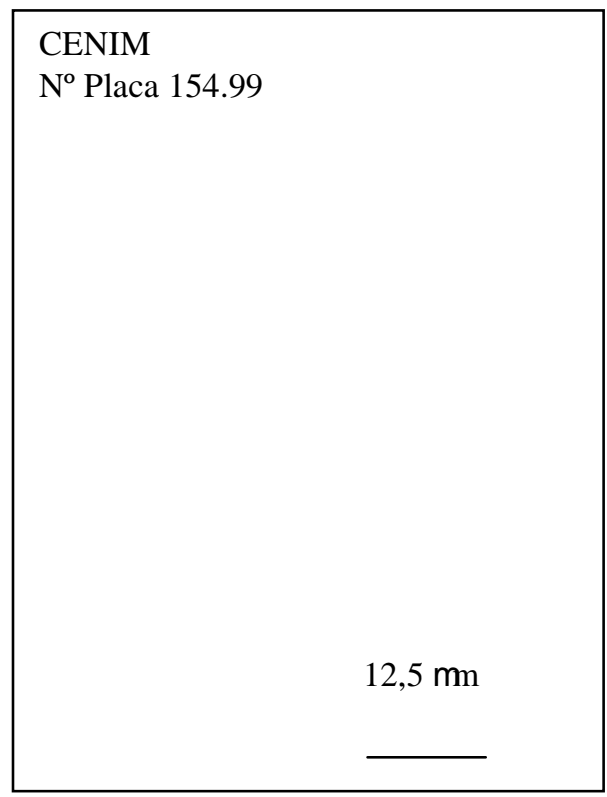

(b)

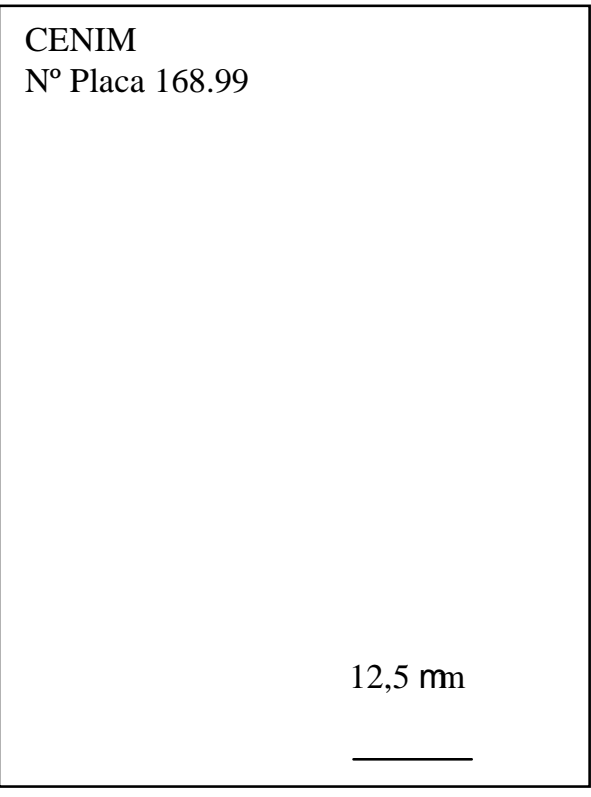

(c)

Figure 4. Microstructures obtained in steel B after continuous cooling at a) $6{ }^{\circ} \mathrm{Cs}^{-1}$, b) $3{ }^{\circ} \mathrm{Cs}^{-1}$ and c) $0.75^{\circ} \mathrm{Cs}^{-1}$.

All these results show the difficulties encountered to produce fully acicular ferrite microstructures by continuous cooling, using industrially reproducible cooling rates, even in steels as studied here which present a resistance to bainite formation. The Mo delays the formation of allotriomorphic ferrite but, on the other hand, favors the presence of martensite in the final microstructure. To prevent martensite formation, a two stage cooling cycle or isothermal treatments can be applied. As reported elsewhere ${ }^{1}$, the two stage cooling cycles with the first cooling performed at $10 \mathrm{Cs}^{-1}$ from the austenitizing temperature to one in a range $400-500{ }^{\circ} \mathrm{C}$, followed by a second cooling at $2 \mathrm{Cs}^{-1}$ from this to room temperature have demonstrated to be useful in producing acicular ferrite microstructures.

Isothermal treatments have been carried out to investigate comparatively the behavior of both steels and the effect of the Mo on the acicular ferrite microstructure. The microstructural compositions obtained with the isothermal treatments carried out at temperatures in the range $500-400{ }^{\circ} \mathrm{C}$ are shown in Table 2 for both steels. It can be seen that, for temperatures lower than about $450^{\circ} \mathrm{C}$, the microstructure is mainly acicular ferrite. Above this temperature, different mixtures of ferrite, pearlite and acicular ferrite form. The final microstructures obtained for a holding time of $20 \mathrm{~min}$ at $450{ }^{\circ} \mathrm{C}$ are shown in Fig. 5 for both steels. It can clearly be seen in the micrographs that Mo not only affects the transformation kinetics, as seen before, but also modifies the morphology of the transformation product. Steel A exhibits a microstructure after this treatment formed by the well known randomly oriented ferrite plates while steel B develops packets formed by different parallel sub-units. This type of 
microstructure can be erroneously interpreted as being bainite if the evolution of the transformation is not carefully followed from the early stages. At this stage, the places where the nucleation takes place makes the difference between bainite and acicular ferrite. Looking at the partially transformed microstructures produced by interrupted isothermal tests, see Fig. 6, it can be seen that primary acicular ferrite plates in steel A nucleate on the second phase particles.

These have been identified as being MnS particles covered by a shell of CuS. This shell seems to be favorable in terms of acicular ferrite formation, as discussed elsewhere [2,3]. The same type of particles also produces AF nucleation in steel B [17]. It has been shown that the transformation can progress in two different ways through the autocathalityc nucleation of new plates in different orientations to the primary ones or by the formation of subunits parallel to them [18]. In the first case, The result is the typical interlocking microstructure of acicular ferrite that can be seen in Fig. 5(a) for the steel A at $450{ }^{\circ} \mathrm{C}$. Steel B behaves according to the second type of morphology.

Table 2. Constituents of the final microstructures after isothermal heat treatments.

\begin{tabular}{|c|c|c|}
\hline \multirow[t]{2}{*}{ Temperature $\left({ }^{\circ} \mathrm{C}\right)$} & \multicolumn{2}{|c|}{ Microstructure } \\
\hline & Steel A & Steel B \\
\hline 500 & $\mathrm{P}, \mathrm{AF}, \mathrm{F}$ & AF (SPP), P \\
\hline 450 & $\mathrm{AF}$ & AF (SPP) \\
\hline 400 & $\mathrm{AF}$ (SPP) & AF (SPP) \\
\hline
\end{tabular}

\section{CEIT}

Fig. 5: (a)20 min a $450{ }^{\circ} \mathrm{C}$. Steel A

\section{$\dot{i} ? \mu \mathrm{m}$}

(a)

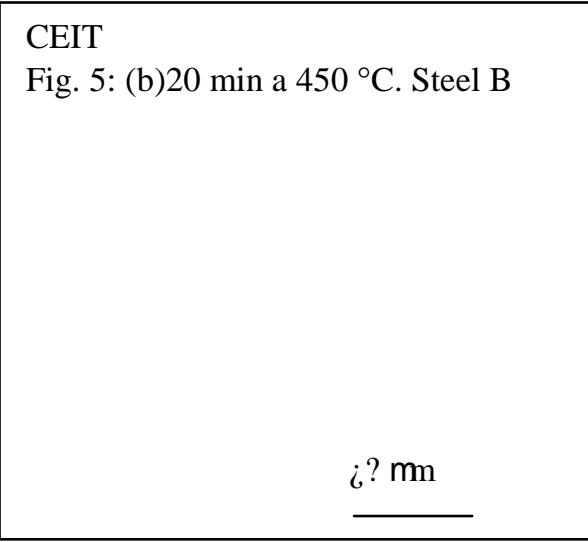

(b)

Figure 5. Final microstructures obtained by isothermal treatment during 20 min at $450{ }^{\circ} \mathrm{C}$ a) steel A and b) steel B.

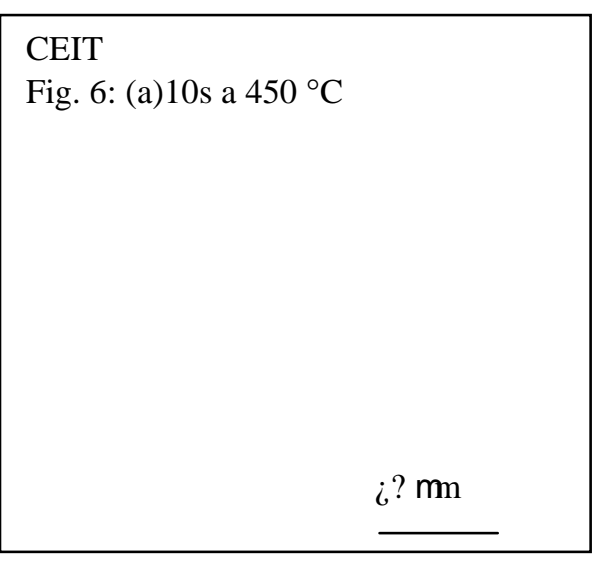

a)

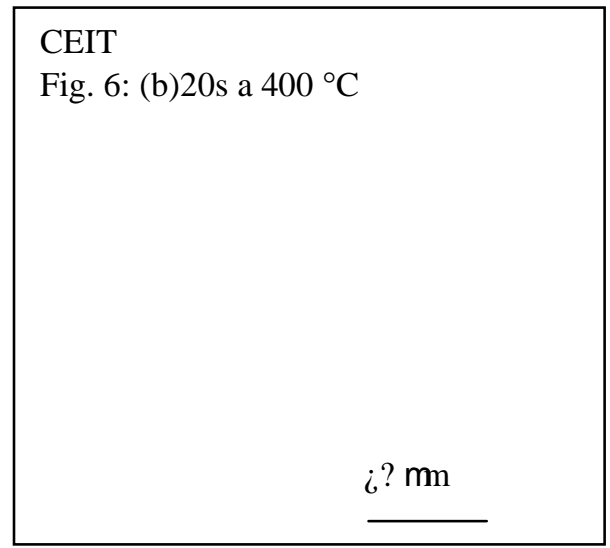

b)

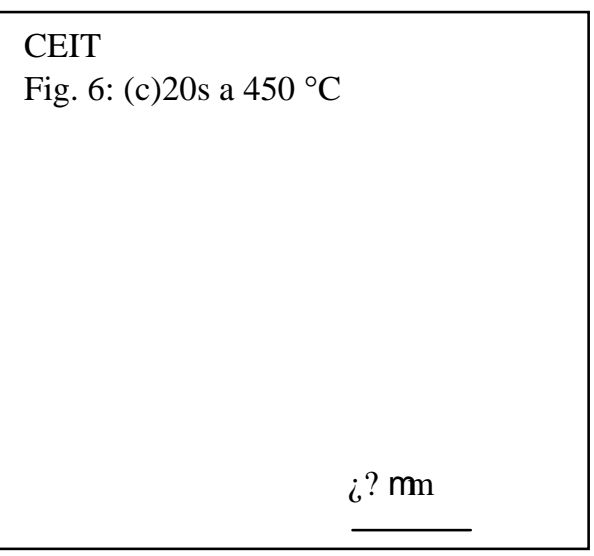

c)

Figure 6. Optical micrographs a) steel A held during 10 s at $450^{\circ} \mathrm{C}$, b) steel A held during $20 \mathrm{~s}$ at $400{ }^{\circ} \mathrm{C}$ and c) steel $\mathrm{B}$ held during $20 \mathrm{~s}$ at $450{ }^{\circ} \mathrm{C}$ followed in all the cases by water quenching. 
The formation of sheaves or packets constituted by ferrite subunits is not exclusive of Mo containing steels but can also been observed in other steels, depending on the transformation temperature. This is illustrated in Fig. 6(a) and 6(b). Individual plates develop in steel $\mathrm{A}$ at $450^{\circ} \mathrm{C}$ but sheaves form in this steel during the isothermal treatment at $400{ }^{\circ} \mathrm{C}$. As discussed elsewhere [19], the transition between both morphologies is associated to the transition between upper and lower acicular ferrite. The first leads to the formation of plates, and the second of sheaves.

This transition between both types of transformation relates to the carbon mobility which is expected in turn to depend not only on the treatment temperature but also on the steel composition. As can be seen in Fig. 6(c), the Mo containing steel presents an evolution of the transformation at $450{ }^{\circ} \mathrm{C}$ similar to that exhibited by the steel A at $400{ }^{\circ} \mathrm{C}$. The same type of SEM and TEM analysis carried out previously $[18,19]$ is now under progress for Mo containing steel. However, according to the present results, it seems that the addition of Mo has raised the temperature of transition between upper and lower acicular ferrite and consequently the temperature of formation of sheaves instead of plates.

\section{Conclusions}

1- Acicular ferrite has been obtained by both isothermal and continuous cooling treatments in two medium carbon microalloyed forging steels.

2- Molybdenum not only affects the transformation kinetics but also modifies the morphology of the acicular ferrite.

3- Molybdenum favors the acicular ferrite formation but increases the amount of martensite being present in the final microstructure. In Mo containing steel, the formation of this phase is the main variable limiting the design of useful cooling cycles in order to get microstructures with enhanced mechanical properties.

\section{Acknowledgements}

The authors acknowledge financial support from the Spanish Comisión Interministerial de Ciencia y Tecnología (CICYT) (project-PETRI 95-0089-OP). GSB Acero S.A is thanked for providing the steel and its collaboration in this project.

\section{References}

1. Madariaga I, Gutierrez I, Garcia de Andres Cand C. Capdevila, Scripta Metall.et Mater, 1999, 41:229.

2. Madariaga I and Gutierrez I, Acta Mater., 1999, 47:951.

3. Madariaga I, Gutiérrez I and Romero JL, Metall. Trans., 1998, 29A:1003.

4. Linaza MA, Romero JL, Rodríguez-Ibabe JM and Urcola JJ, Scripta Metall., 1993, 29:1217.

5. Garcia de Andres C, Capdevila C, Caballero FG and San Martin D, J. Mater. Sci., 2001, 36:565.

6. Thewlis G, Mater. Sci. Technol., 1994, 10:110.

7. $\quad$ Zhang Z and Farrar RA, Mater. Sci. Technol., 1996, 12:237.

8. Kinsman KR and Aaronson HI, Transformation and hardenability in steels, Climax Molybdenum co, Ann Arbor, Michigan, 1967:39

9. Paxton HW and Bain EC, Alloying elements in steels, ASM, Metals Park, OH, 1966:274.

10. Bhadeshia HKDH and Waugh AR, in Proc. Int. Conf. on Solid $\rightarrow$ Solid Phase Transformation, Pittsburgh, ASM, Metals Park, OH, 1981:993.

11. Bhadeshia HKDH and Waugh AR, Acta Metall., 1982, 30:775.

12. Stark I, Smith GDW and Bhadeshia HKDH, in Proc. Int. Conf. on Solid $\rightarrow$ Solid Phase Transformation, Institute of Metals, London, 1988:211.

13. Stark I, Smith GDW and Bhadeshia HKDH, Metall. Trans. A, 21A, 1990:847.

14. Josefsson B and Andren HO, in Proc. of the 35th Int. Field Emission Symp., Oak Ridge, TN, 1988: 8.

15. Josefsson B and Andren HO, Recent Trends in Welding Science and Technology, ASM, OH, 1989:243.

16. Ricks RA, Howell PR and Barrite GS, J. Mater. Science, 1982, 17:732.

17. Madariaga I, PhD thesis, Univ. Navarra, San Sebastian, Spain, 1999.

18. Diaz-Fuentes M, Madariaga I and Gutierrez I, in Proc. of J.J. Jonas Symposium on Thermomechanical Processing of steels - COM'2000, Met. Soc., Canada, 2000:489.

19. Madariaga I, Gutierrez I and Bhadeshia HKDH, Metall. Trans. A, in pres, 2001. 